\title{
- Recent Advances in Dentistry for better Oral Health
}

\section{Prashant Babaji ${ }^{1}$, Samrat Hegde ${ }^{2}$}

IJCRR

Section: Healthcare ISI Impact Factor (2019-20): 1.628 IC Value (2019): 90.81 SJIF (2020) $=7.893$

'Professor, Department of Pediatric Dentistry, Sharavthi Dental College and Hospital, Shivamogga, Karnataka, India. E-mail: babajipedo@gmail.com

${ }^{2}$ Principal, Department of Conservative Dentistry, Sharavthi Dental College and Hospital, Shivamogga, Karnataka, India.
Dental caries is the most wide spread chronic disease affecting mankind. The significant objective in dentistry is to deliver best dental care to the patients. This can be achieved with the help of a trained dental professional. Developments in science and technology has resulted in to various innovations in materials, drugs, and techniques in dentistry to improve oral health.

Toady's concept has changed from GV Blacks concept of extension for prevention to prevention of extension with advances in restorative materials. Various newer non fluoridated remineralizing agents such as; Casein Phosphopeptide Amorphous Calium Phoshphate (CPP-ACP), Bioactive Glass and Tricalcium Phosphate, helped for caries prevention. ${ }^{1}$ Implementation of rotary endodontics with several NiTi instruments (Mtwo, Waveone) helped in endodontic practice. ${ }^{2}$ Developments of instruments and policies are aimed to deliver antibiofilm effects and provide good radicular dentin structure. Substantial developments in regenerative endodontics permit better accepting of a multitude of factors that direct stem cell-mediated regeneration and repair the damaged pulp-dentin complex. ${ }^{3}$

Nowadays, dental implants are gaining importance for replacement of missing teeth. The most regularly used implant systems comprise Nobel Biocare, BioHorizon, AstraTech, Straumann, Bicon, BIOMET 3i, Zimmer and Interlock. The long-term survival of dental implants depends on the dentist skill, implant (quality, type) and patient's factors (systemic condition, smoking habit). Regular monitoring of the patient for minimizing the incidence of implant loss and by treating peri-implant pathology in a timely means are the main therapeutic objectives. ${ }^{4}$

Oral cancer has also long been achief problem in worldwide because of changes in lifestyle. Higher incidence of oral carcinoma and its late-stage appearance are the main worldwide healthcare concerns. Recent advances in optical imaging systems, such as tissue-fluorescence imaging, Microarrays, Nanodiagnostics, and optical coherence tomography, have been proved to be considerbly efficient. Considerations should be directed towards public awareness about oral cancer, oral examination and screening for early diagnosis and prevention. ${ }^{5}$

\section{REFERENCES}

1. Joshi S, Pendyala G, Vidyasagar M, Padmawar N, Nara A et al. Remineralizing agents in dentistry: A review. Remineralizing agents in dentistry: A review. International Journal of Applied Dental Sciences. 2018; 4(2): 198-199.

2. Pathak S. In vitro comparison of K-file, Mtwo, and WaveOne in cleaning efficacy and instrumentation time in primary molars. CHRISMED J Health Res 2016;3:60-4.

3. Kishen A, Peters OA, Zehnder M, Diogenes AR, Nair MK. Advances in endodontics: Potential applications in clinical practice. J Conserv Dent.2016;19:199-206.

4. Gulati M, Govila V, AnandV, Anand B. Implant Maintenance: A Clinical Update. International Scholarly Research Notices. Volume 2014, Article ID 908534, page 8. http://dx.doi. org/10.1155/2014/908534

5. Chakraborty D, Natarajan C, Mukherjee A. Advances in oral cancer detection. Adv Clin Chem. 2019;91:181-200. 